\title{
THE EFFECTS OF NOISE REDUCTION ON SOCIAL BEHAVIORS
}

\author{
An abstract of a Thesis by \\ Vincent $\mathrm{J}$. Carbone \\ January 1983 \\ Drake University \\ Advisor Phillip K. Duncan
}

The problem. Previous researchers have suggested that noise level reduction is correlated with generalized improvements in untreated social behaviors. It is not clear that this generalized effect can be assumed with different behaviors in different settings. In addition, the results of previous studies were obtained by utilizing interval time sampling measurement procedures as opposed to continuous recording.

Procedure. Electro-mechanical equipment was wired to a stereo in the recreation room of a juvenile shelter care facility. The equipment continuously measured the frequency and durations of disruptions above $85 \mathrm{db}$ during treatment phases. In addition several corollary social behaviors were continuously measured by trained observers. A contingency of reinforcement was placed on a social behavior in the latter phases of the experiment.

Findings. A repeated time series design (reversal) demonstrated experimental control of disruptions above $85 \mathrm{db}$. However, no change was found in the level of social responding until a direct contingency of reinforcement was applied.

Conclusion. Corollary social behaviors did not show a generalized effect of the contingencies placed upon disruptions above $85 \mathrm{db}$. The contradictory findings of previous research may be the result of measurement procedures and not differences in responding.

Recommendations. It can not be anticipated that a reduction of noisy disruptions will lead to a generalized enhancement of social responding. Moreover, noise reduction researchers should utilize continuous recording procedures to measure changes in corollary social behaviors. 


\title{
THE EFFECTS OF NOISE REDUCTION \\ ON SOCIAL BEHAVIORS
}

\author{
A Thesis \\ Presented to
}

The School of Graduate Studies

Drake University

In Partial Fulfillment

of the Requirements for the Degree

Master of Arts

by

Vincent J. Carbone

January 1983 


\section{TABLE OF CONTENTS}

PAGE

INTRODUCTION AND REVIEW OF THE LITERATURE . . . . . . . 1 METHOD . . . . . . . . . . . . . . . . . . . . . . 5 RESULTS . . . . . . . . . . . . . . . . . . . . . . 11 DISCUSSION . . . . . . . . . . . . . . . . . . . . . 17 REFERENCE NOTES . . . . . . . . . . . . . . . . . . . . 22 REFERENCES . . . . . . . . . . . . . . . . . . . . . . 23 


\section{THE EFFECTS OF NOISE REDUCTION \\ ON SOCIAL BEHAVIORS}

by

Vincent $J$. Carbone

Approved by Committee:

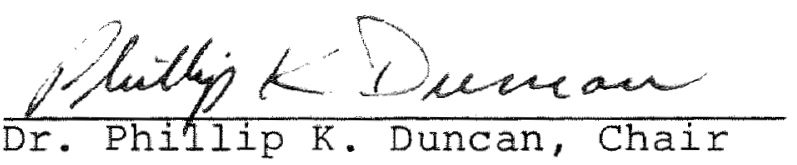

Dr.W. Scott wood

Dr. Karen Connor 


\section{LIST OF FIGURES}

Figure

Page

1. The number of disruptions above $85 \mathrm{db}$ during daily recreation sessions. . . . . . . . . 12

2. The total session duration in seconds above $85 \mathrm{db}$................. . . 13

3. The ratio of games played to youths present . - 15

4. The average number of youths present during daily recreation sessions ........... 16 
CHAPTER I

INTRODUCTION

Noise has become a serious enough problem to gain the attention of many researchers. Excessive noise has been linked to not only changes in work performance (Broadbent \& Little, 1960; Kovirgin \& Mikheyev, 1965) but also measurable physiological stress reactions (Glass \& singer, 1972).

However, only a few behavioral researchers have attempted to address this problem using the technology of behavior analysis (Schmidt \& Ulrich, 1969; Wilson \& Hopkins, 1973; Meyers, Artz \& Craighead, 1976; Carbone \& Todd, in press; Greene, Bailey \& Barber, 1981; Bleier \& Duncan, Note 1). These studies all found that the application of behavioral principles were effective in decreasing disruptive noise.

Both the Schmidt and UIrich (1969) and wilson and Hopkins (1973) studies demonstrated the reduction of noise in classroom settings. When the elementary students in the Schmidt and Ulrich (1969) experiment maintained a noise level below $42 \mathrm{db}$ for ten minutes they received two additional gym period minutes and a two minute class break. The resulting effect was a decrease from a mean of $52.5 \mathrm{db}$ to a mean of $39 \mathrm{db}$.

Wilson and Hopkins (1973) automated their procedures using a voice operated relay (VOR) to shut off a classroom 
radio when noise exceeded the criteria. With pre-set criterion levels adjusted to $76 \mathrm{db}$ in one room and $70 \mathrm{db}$ in another they demonstrated a substantial reduction in noise during the radio contingent phases of the experiment.

In another study which used a VOR, Meyers et al. (1976) demonstrated effective control over the noise level of college dormitory floors occupied by undergraduate females. The students on three floors were eligible for either a monetary payment or credit towards a psychology class if they maintained noise levels below $82 \mathrm{db}$. A fourth floor merely received feedback. The VoR rang a bell each time the criterion was transgressed. All four floors showed a reduction in noise with the feedback only group showing the least effect.

Carbone and Todd, (in press) demonstrated a 50\% reduction in noise level of an elementary school cafeteria of 350 students. Cartoon viewing during meal time was made contingent upon a noise level of less than $72 \mathrm{db}$ in the cafeteria. Each time the sound level exceeded the criterion the cartoons shut off until the noise fell below $72 \mathrm{db}$. subjective ratings of teachers showed a change from "very irritating" to "very pleasant" as a function of baseline and treatment phases respectively.

Greene et al. (1981) provided visual feedback (light display), contingent music and raffle incentive to 44 middle school bus riders. The reinforcers were presented 
contingent upon maintaining a noise level less than $86 \mathrm{db}$ during a 25-minute bus ride. Using a repeated time series design they demonstrated a substantial reduction in out-ofseat and rough-housing behaviors by the children with a similar reduction in noisy disruption. The results were comparable to the first experiment.

Bleier and Duncan (Note 1) wired a VOR to a stereo system in a juvenile shelter care facility where 20 male and female juveniles resided. During treatment phases, stereo music was contingent upon maintaining a sound level of less than $85 \mathrm{db}$ during an evening recreation period. Using a repeated time series design they demonstrated a substantial reduction in the number of transgressions above $85 \mathrm{db}$. Although measures of staff behavior were obtained (token fines and time-outs) no direct measures of related changes in social behaviors were reported.

$$
\text { Michelson, Dilorenza and Calpin (1981) effectively }
$$

reduced the lunchroom noise of 14 emotionally disturbed/ learning disabled children in an inpatient unit. A repeated time series design demonstrated the successful reduction of disruptions above $76 \mathrm{db}$ when treatment phases included feedback and a contingent mid-afternoon snack of ice cream. Although the experiment did not produce a reduction in the duration of time above the $76 \mathrm{db}$ criteria, it did achieve an increase in lunchroom appropriate behavior.

The studies of Greene et al. (1981) and Michelson et al. 
(1981) are intriguing since they suggest that noise level reduction is at least highly correlated with generalized improvements in socially desirable behaviors. These findings are particularly interesting since there was no contingency specifically designed to improve social responses. The corollary behaviors measured by Greene et al. (1981) and Michelson et al. (1981) appeared to have been included in the same operant class as loud vocalizations (Skinner, 1955; Schick, 1971). It is still unclear as to whether all corollary social behaviors in a different setting can be assumed to be a member of the same operant class as loud vocalizations.

A factor clouding an understanding of the precise relation between decreased noise, decreased negative social behaviors and increased positive social behaviors is that both Greene et al. (1981) and Michelson et al. (I981) used an interval time sampling procedure to measure social responses. This procedure has been shown to seriously distort dimensions of actual behavioral events (Powell, Martindale \& Kulp, 1975; Powel1, Martindale, Martindale \& Bauman, 1977; Springer, Brown \& Duncan, 1981).

The present study was designed to further investigate the effect of time-out or noise disruptions and appropriate social responses. Specifically, both disruptions specific contingencies and social response specific contingencies were investigated. In addition, the desirable social responses were monitored via continuous measurement procedures. 
CHAPTER II

METHOD

\section{Subjects}

The subjects for this experiment were male and female juveniles residing at the shelter care facility of the Polk County Juvenile Home, Des Moines, Iowa. All youths had been court ordered to the Juvenile Home pending court proceedings regarding their disposition. The average length of stay is 25 days with several youths remaining for longer and shorter periods of time. The facility is licensed for a capacity of 20 juveniles.

\section{Setting}

Each phase of the study was conducted each evening between 8:00-10:00 PM during a recreation period. The residents were required to remain in the recreation room for one-half hour periods.

The study was conducted in a $6.5 \mathrm{~m} \times 8.6 \mathrm{~m}$ recreation room in Juvenile Hall. The recreation room contained both table games i.e. checkers, chess, etc., and large recreational games, i.e., pool, air hockey, foosball.

As part of the recreational period, staff frequently would turn on the stereo (Electrophonic R82303) system to provide radio music during the recreation period. Only staff had access to the equipment which was placed in a 
locked cabinet.

\section{Apparatus}

A Lafayette voice operated relay (VOR) (Model \#18010) was wired to the stereo system in such a way that the stereo would automatically shut off when the sound level in the room exceeded the pre-set level of 85 decibels. The level of $85 \mathrm{db}$ was selected because the staff had reported that noise above that level was considered unpleasant. The VOR microphone was hidden in a hollowed-out ceiling tile $2.5 \mathrm{~m}$ from the floor and $3 \mathrm{~m}$ from one speaker and $4 \mathrm{~m}$ from the other. An electro-mechanical counter activated each time the preset level had been transgressed. The VOR was calibrated at the beginning of each experimental phase. The VOR also operated an electro-mechanical timer and a clock. Each time the sound level exceeded the pre-set criterion the timer would activate for a designated time-out period while the stereo was off. Any sound which exceeded the criterion level during the time-out interval would re-set the timer for another full period. In addition, the clock would activate for the duration of time that the sound level remained above the pre-set criterion.

\section{Principal Dependent Variables}

Number of Disruptions - The frequency of disruptions above $85 \mathrm{db}$.

Time Above Pre-set Level - Elapsed time accounted for 
by disruptions above $85 \mathrm{db}$.

Ratio of Games Played to Residents Present - The

number of games played per recreation period divided

by the average number of youth present.

\section{Additional Behaviors Measured}

In addition to disruptions, several resident and staff behaviors were measured.

Pushing - A resident placing any part of his/her body against another resident and exerting force which may be sufficient to move the second youth.

Arguing - A quick interchange of comments between or among two or more residents when a harsh tone of voice is used in discussing an issue upon which they do not agree.

Mean Duration of Arguments - The average amount of time that elapses between the first comment and the last comment of the arguments recorded during each recreational period.

Staff Coercive comments - The number of times during a recreation period that staff threaten, warn, reprimand, remind and command residents to behave appropriately. Average Number of Youth Present - Average number of youths present during four consecutive one-half hour periods. 
Measurement and Observational Techniques

The number of disruptions and the elapsed time above the pre-set $d b$ level were measured by electro-mechanical equipment. This information was recorded by a staff member following each session.

The staff and resident behaviors were recorded by trained observers. An observer, equipped with a clipboard, coded data sheet and stopwatch would place him/herself in the recreation room at the beginning of the recreation period each evening. The observer would record the frequency of arguments, pushes and staff coercive comments in 15 minute blocks for the entire recreation period. The duration of arguments was recorded by starting and stopping the stopwatch at the beginning and ending of arguments and recording the digitally presented time.

In addition, the observer would record the number of youths present at the start of each one-half hour block of time.

The observer also recorded the number of residents who requested to play a game within each 15 minute block of time.

\section{Observer Agreement}

Observer agreement was assessed at least once during each phase of the experiment. In addition, observer agreement was assessed on several days during periods of notable variability. 
Observer agreement for all measures was assessed through simultaneous but independent observations by a second recorder. Observer agreement was calculated by using the block-by-block agreement method (Bailey \& Bostow, 1980). The smaller Erequency or duration was divided by the larger within each block and then averaged across blocks. Observer agreement averaged $92 \%$ with a range of 84-98\%.

Experimental Conditions

Experimental design. The effects of the treatment procedures were assessed through a repeated time series (reversal) design. Following an initial baseline period the experimental procedure was alternated with baseline conditions. During the experimental phases the stereo shut off procedures were implemented while during baseline conditions excessive noise had no effect upon the availability of music.

Baseline 1 . The youngsters were informed that the staff of the Juvenile Home were interested in improving the program and consequently an observer would be recording some information each evening. In addition, the youngsters were informed that the observer would not be able to tell them anything about the information.

During this phase all of the dependent variables were measured however a disruption above $85 \mathrm{db}$ did not shut off the stereo. 
$30 \mathrm{Sec}$ Stereo Shut-off. On the first day of this phase the youngsters were informed that excessive noise would shut off the stereo for a short period of time (30 seconds). Baseline $_{2}$. The equipment was modified so that disruptions would not shut off the stereo.

$30 \mathrm{sec}$ Stereo Shut-off. Same as previous $30 \mathrm{sec}$ Stereo Shut-off phase.

$30 \mathrm{Sec}$ Stereo Shut-off and $\mathrm{S}^{\mathrm{R}+}$ Games. On the first day of this phase a contingency of reinforcement was placed on game playing. The youngsters were informed that each game they played would result in a fifty token point bonus. Fifty token points was approximately 5\% of their daily earnings. The bonus points could then be exchanged for other activities.

Baseline $_{3}$ and $\mathrm{S}^{\mathrm{Rt}}$ Games. This phase was the same as baseline, while the contingency of reinforcement for the game playing was continued.

$5 \mathrm{Sec}$ stereo Shut-off and $S^{R+}$ Games. On the first day of this phase the apparatus was modified so that disruptions would shut off the stereo for 5 seconds rather than 30 seconds. The contingency of reinforcement on games was continued. 
CHAPTER III

RESULTS

Figure 1 represents the number of disruptions each day that exceeded the $85 \mathrm{db}$ level. A clear alternating pattern across conditions is evident when baseline and treatment phases are compared. The baseline phases of the experiment averages $105.7,111.9$ and 116.2 disruptions while the treatment phase averaged $42.0,49.3$ and 33.4 disruptions respectively. The ranges for the baseline phases were 60-172, $12-$ 233, 96-136 and the ranges for the treatment phases were $11-88,37-61$, and $14-60$.

Figure 2 represents elapsed time above $85 \mathrm{db}$ for each experimental session. An alternating pattern similar to that in Figure 1 was established across conditions. The first baseline phase averaged $169 \mathrm{sec}$ per session above the shut off criterion. The first treatment phase reduced the elapsed time to an average of 79 sec per session. When the stereo shut off contingency was removed in the second baseline phase the duration of time above criteria increased to an average of $150.4 \mathrm{sec}$ per session. Reinstatement of the shut-off condition aropped the average time to 78.1 sec per session. The final baseline and treatment phases of the experiment showed a similar pattern with time above criterion durations of 154.1 and 24.28 sec per session respectively. 


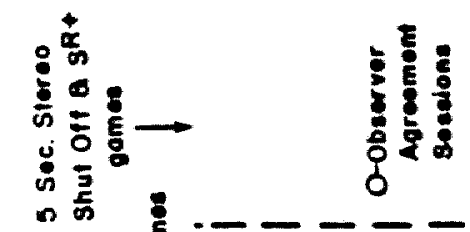

$*$

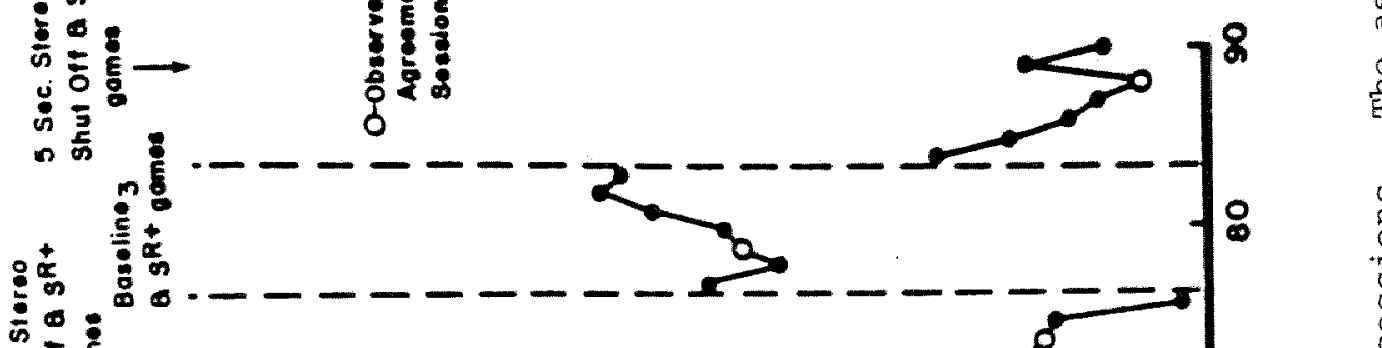

:흥

용
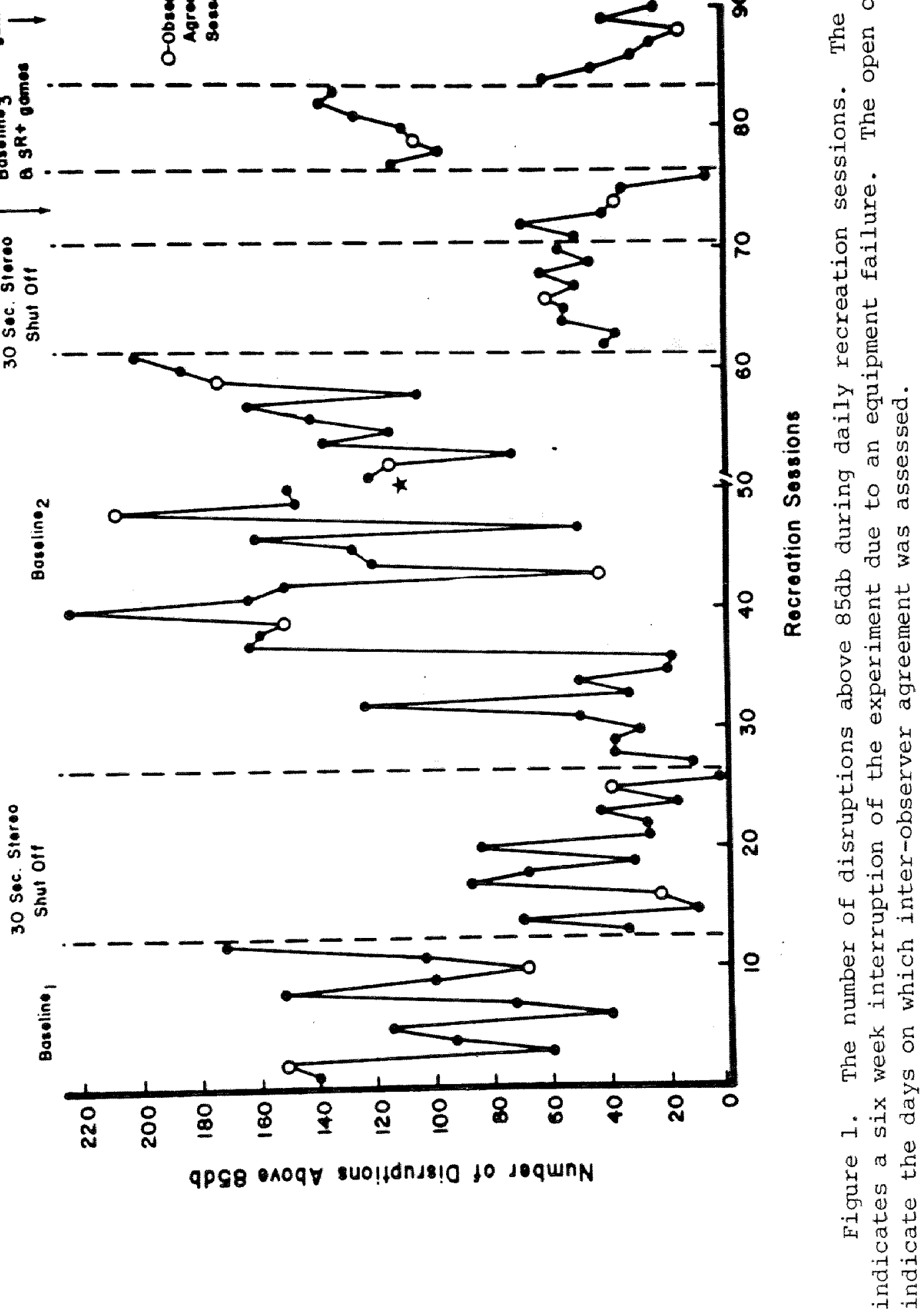

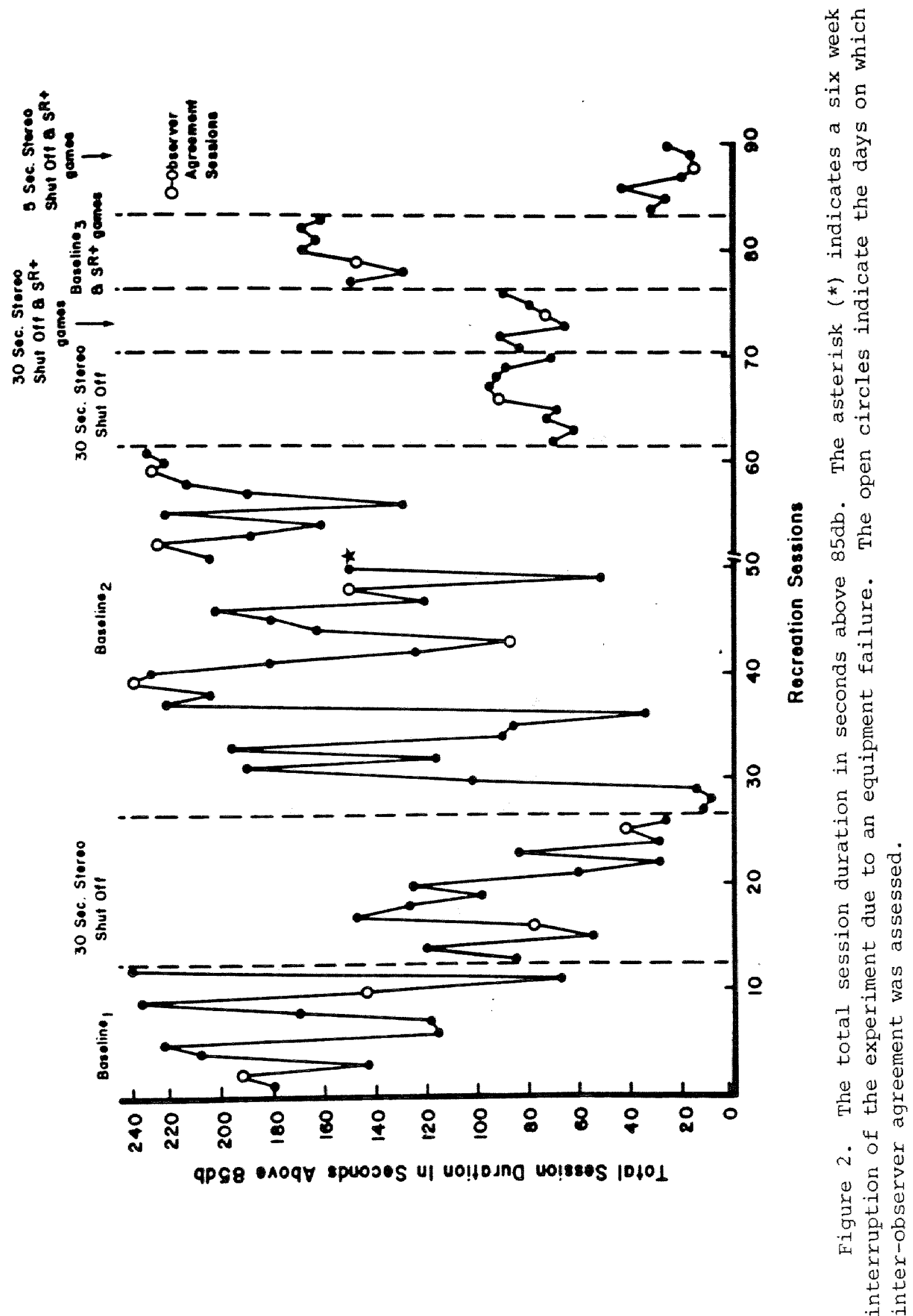
Figure 3 represents the ratio of the number of games played to the mean number of youths present each session. The average number of games played remained fairly consistent across the first 3 phases of the experiment, $3.4,3.9$ and 2.7 respectively. When a 50-point bonus was awarded for game playing on the tenth day of the second treatment phase the average rose to 5.0. This contingency of reinforcement remained in effect for the last baseline and treatment phases. During both of these phases, the average number of games played was higher than the period prior to the application of the contingency of reinforcement. The last baseline phase averaged 5.7 while the last treatment phase averaged 5.1 .

Figure 4 represents the average number of youth present during the evening recreation periods. On the average, approximately 8 children were present during each evening recreation period across all phases of the experiment.

As indicated above, several other behaviors of both residents and staff were measured. The frequency of residents arguing and pushing remained at a fairly consistent low rate across all conditions of the experiment. Moreover, the frequency of staff coercive comments did not vary across the experimental conditions of this experiment. Therefore, these data were not presented graphically. 

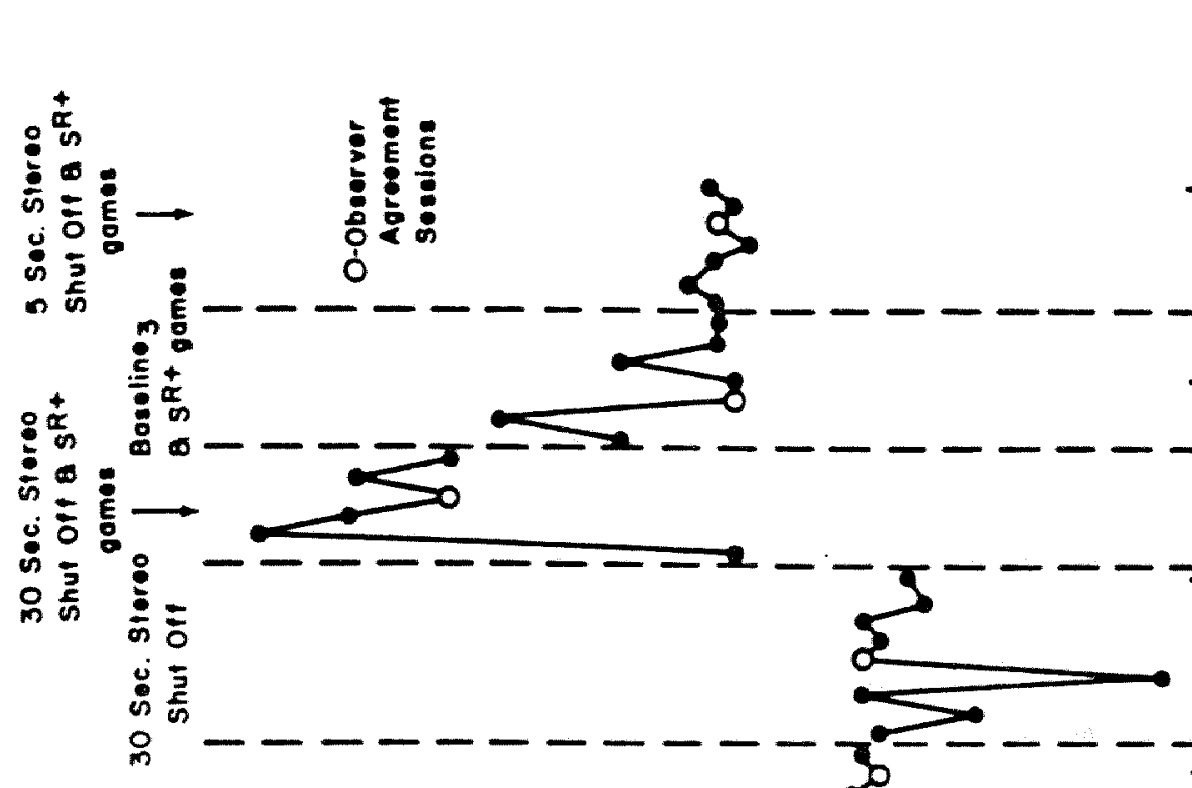


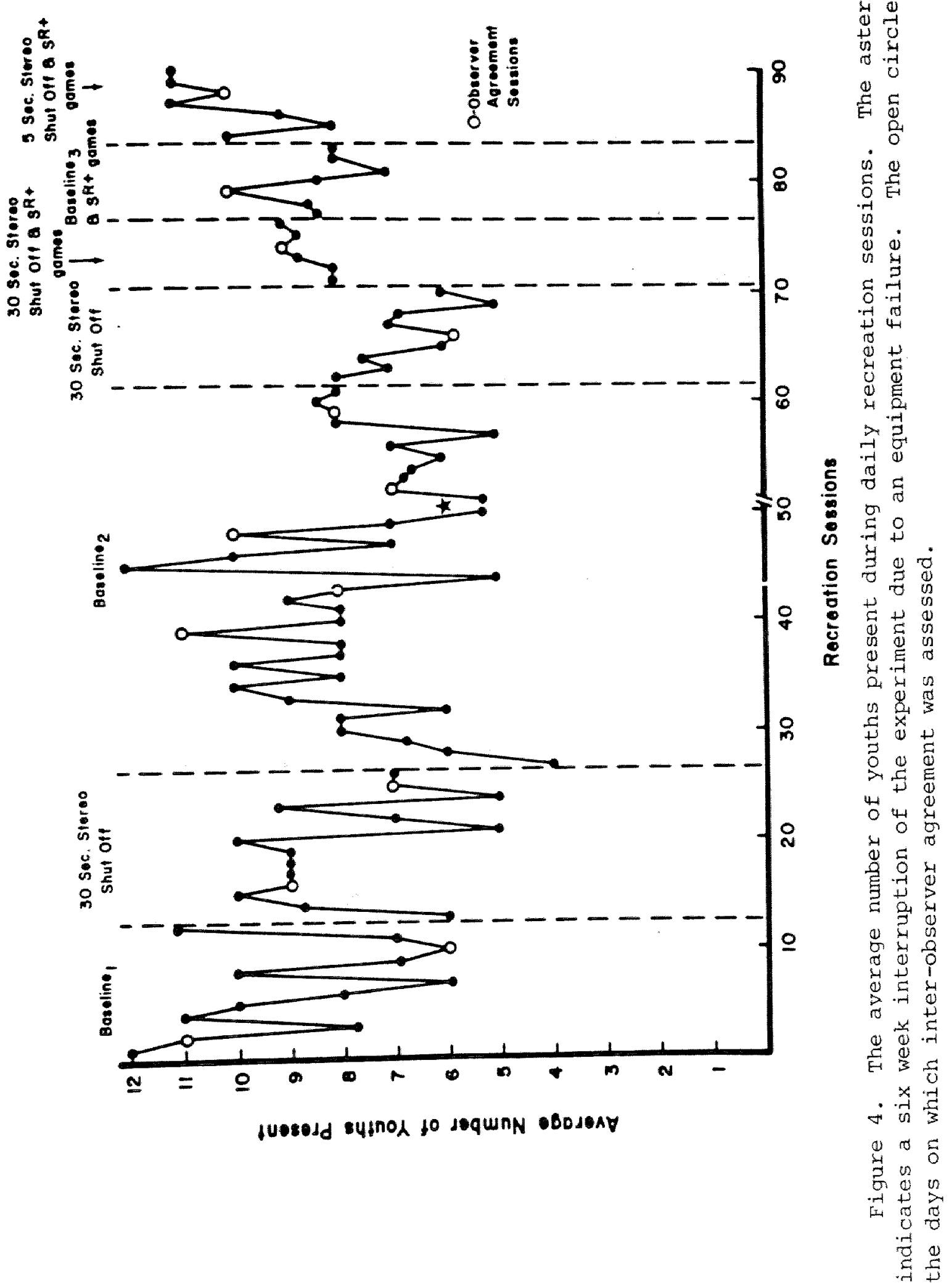


CHAPTER IV

\section{DISCUSSION}

The results of this study are consistent with the findings of previous research (Greene et al., 1981; Michelson et al., 1981; Bleier \& Duncan, Note 1). Disruptive noise was substantially reduced as a function of the treatment procedures (stereo shut-off). In addition, the findings appear to support the notion of a dependent relationship between frequency of disruptions and their duration. In this experiment, the duration of time above the $85 \mathrm{db}$ criterion co-varied with the frequency of disruptions across all phases of the study. These findings support the results reported by Greene and Bailey (1981), however, they are not consistent with Michelson et al. (1981) assertion regarding the independence of frequency and duration of noise.

An issue of greater importance is the relationship between noise reduction and other significant social behaviors. The previous studies cited above reported a substantial modification in the occurrence of maladaptive social behaviors during treatment phases in which a contingency was placed upon only disruptions. Greene et al. (1981) reported that roughhousing and out-of-seat behavior on a school bus could be substantially reduced by merely reducing 
the number of disruptions. In addition, they reported a reduction in bus driver coercive comments. Michelson et al. (1981) reported that appropriate lunchroom behavior could be enhanced by reducing the frequency of outbursts. The results of this study do not support these findings. While several relevant social behaviors were assessed throughout the experiment none of the behaviors appeared to be effected directly by the frequency or duration of disruptions. Under the conditions of this study, there does not appear to be a dependent relationship between noise reduction and other significant social behaviors.

Once experimental control of noise reduction had been demonstrated in this study and after no substantial change was evident in social behaviors, a positive contingency of reinforcement was placed on the social behavior of game playing. As shown in Figure 3, there was an immediate increase in game playing when the contingency was applied. This effect stabilized and was consistent across the remainder of experimental conditions. While issues of experimental design preclude precise verification of the effectiveness of the contingency, an interesting point is raised. During the last baseline period for noise reduction the contingency on games was continued. It is interesting to note that game playing did not decrease to previous baseline levels while noise did increase to prior levels. Consequently, these findings lend support to the notion that the contingency 
appears to have been effective and more importantly the frequency and duration of disruptions appear to exert little influence over the other relevant social behaviors.

These data indicate that in some situations it is not valid to assume that noise reduction will be directly related to changes in other behaviors without implementation of a direct intervention for those behaviors. There may be several explanations which could account for the contradictory findings.

First of all, the differences in the settings and subjects studied may account for the discrepant results. It is conceivable that there are inherent characteristics of midale school children on a school bus and emotionally disturbed/learning disabled children in a lunchroom which accounts for the contradictory findings.

Moreover, the rather low interobserver agreement percentages reported by Greene et al. (1981) reduce confidence in the accuracy of the findings. On several occasions interobserver agreement was found to be low as $33 \%$. Consequently, it is difficult to determine whether or not the data reported are an accurate reflection of the responding by the youngsters.

A third explanation is related to measurement procedures. In the present study all corollary social behaviors were measured using continuous recording procedures. In other words, all occurrences of the behaviors were recorded 
regardless of their frequencies or durations. Both previous researchers (Greene et al., 1981; Michelson et al., 1981) employed interval time sampling procedures. Greene et al. (1981) used a 15 second partial interval time sampling procedure in which any occurrence of the behavior within the interval would score that interval. This method of measurement has been seriously criticized for its inaccuracy of estimation (Powell et al., 1975, 1977; Springer et al., 1981). When interval time sampling data has been compared to continuous recording it has been found to inaccurately reflect the continuous measure. The response dimensions of frequency and duration tend to interact with the recording procedure and consequently result in a biased description of behavior (Powell et al., 1978; Springer et al., 1981).

Michelson et al. (1981) may have attempted to overcome these problems by employing a variation of the whole interval recording procedure. They scored 10 second intervals if the behavior occurred for at least 9 of the 10 seconds. Once again the frequencies and duration of these behaviors are confounded and the recording procedures render an uninterpretable index of social responding.

The discrepancies in findings between the present study and previous research related to corollary social behaviors may in fact be an artifact of the procedures used to measure social responses. Future researchers in this area should use continuous recording methods for ancillary 
social behaviors in order to provide maximum credible data to support the issues under study.

The shut-off of the stereo during the treatment conditions could be considered a brief time-out period. Consequently, the parameters of the time-out, e.g. duration, is an area needing investigation in noise control research. In this study the duration of time-out (stereo shut-off) was changed from 30 seconds to 5 seconds only in the last treatment phase. The results suggest that a 5 second shut-off had at least as good as, if not greater suppressive effect than 30 seconds. Although the experimental procedures were not sufficient to allow a more precise analysis this apparent effect should not be ignored.

Previous time-out researchers (White, Nielsen \& Johnson, 1973) who have investigated the parameter of timeout duration found a decrease in the effectiveness of shorter timeouts that were preceded by longer ones. Although the data contained in this study could not be said to refute this finding, they do suggest the need to examine this area more closely. Future researchers may want to exert greater experimental control to empirically determine if shorter time-outs are effective in noise control as suggested by this study. 
Reference Notes

1. Bleier, P., \& Duncan, P. Operant control of noise level in a shelter care facility. Unpublished manuscript, 1980. (Available from Phillip K. Duncan, Department of Psychology, Drake University, Des Moines, Iowa, 50311. 
References

Bailey, J., \& Bostow, D. Research methods in applied behavior analysis. Tallahassee, Florida: Copy Grafix, 1980 .

Broadbent, D. E., \& Little, E. A. J. Effects of noise reduction in a work situation. Occupational Psychology. $1960,34,133-140$.

Carbone, V. J., \& Todd, D. D. The contingent removal and representation of cartoon movies to reduce the noise in an elementary school lunchroom. Education and Treatment of Children, in press.

Glass, D., \& Singer, J. Urban stress: Experiments on noise and social stressors. New York: Academic Press, 1972. Greene, B. F., Bailey, J. S., \& Barber, F. An analysis and reduction of disruptive behavior on school buses. Journal of Applied Behavior Analysis, 1981, 14, 177-192.

Korvirgin, S. E., \& Mikheyev, A. D. The effects of noise level on working efficiency. Report N65-28297, Joint Publications Research Service, Washington, D.C., 1965. Meyers, A. W., Artz, L. M., \& Craighead, W. E. The effects of instructions, incentives, and feedback on a community problem: Dormitory noise. Journal of Applied Behavior Analysis, 1976, 9, 445-451.

Michelson, L., Dilorenza, T. M., Calpin, J. P., \& Williamson, D. A. Modifying excessive lunchroom noise. Behavior Modification, $1981, \underline{5}, 553-564$. 
Powell, J., Martindale, A., \& Kulp, S. An evaluation of time-sample measures of behavior. Journal of Applied Behavior Analysis, 1975, 8, 463-469.

Powell, J., Martindale, B., Martindale, A., \& Bauman, R. Taking a closer look: Time sampling and measurement error. Journal of Applied Behavior Analysis, 1977, 10, $325-332$.

Schick, K. Operants. Journal of the Experimental Analysis of Behavior, 1971, 15, 413-423.

Schmidt, G. W., \& Ulrich, R. E. Effects of group contingent events upon classroom noise. Journal of Applied Behavior Analysis, 1969, 2, 171-172.

Skinner, B. F. Science and human behavior. New York: The Free Press, 1953.

Springer, B., Brown, T., \& Duncan, P. K. Current measurement in applied behavior analysis. The Behavior Analyst, 1981, 4, 19-31.

White, G. D., Nielsen, G., \& Johnson, S. M. Timeout duration and the suppression of deviant behavior in children. Journal of Applied Behavior Analysis, 1972, 5, 111-120. Wilson, C. W., \& Hopkins, B. S. The effect of contingent music on the intensity of noise in junior-high school economics classes. Journal of Applied Behavior Analysis, $1973, \underline{6}, 269-276$. 